\title{
INFLUENCERS, MUJERES Y RUNNING: ALGUNAS \\ CONSIDERACIONES PARA ENTENDER LOS NUEVOS CONSUMOS \\ DEPORTIVOS Y LOS ESTILOS DE VIDA SALUDABLE
}

\author{
INFLUENCERS, WOMEN AND RUNNING: SOME CONSIDERATIONS TO \\ UNDERSTAND NEW SPORT CONSUMPTION AND HEALTHY LIFESTYLES
}

INFLUENCIADORES, MULHERES E CORRIDA: ALGUMAS CONSIDERAÇÕES PARA
ENTENDER O NOVO CONSUMO ESPORTIVO E ESTILOS DE VIDA SAUDÁVEIS

Nemesia Hijós ${ }^{1}$

\section{Resumen}

\begin{abstract}
La apertura lograda por el movimiento feminista ha permitido no solo el crecimiento de la participación femenina en espacios antes vedados, sino también una reconfiguración de los ideales del cuerpo femenino, que continúan en tensión con los estereotipos hegemónicos del cuerpo moderno y atractivo. A pesar de que el running está asociado a una práctica de liberación y encuentro individual, las grandes marcas e industrias deportivas se encargan de reproducir determinadas imágenes colectivas a través de influidores y "embajadores" que imparten consejos en las redes sociales sobre el consumo de ciertos productos asociados a una identidad y estética runner. El objetivo de este trabajo es analizar las representaciones que se construyen a partir del running, prestando atención a la participación de mujeres en esta práctica, sabiendo que el cuerpo es su elemento central y que el mercado tiene un lugar fundamental para pautar las necesidades. Para ello, reflexionaré sobre mis registros de observación de trabajo de campo y analizaré una serie de publicidades, videos e imágenes en las redes sociales (particularmente Instagram y YouTube), donde esta actividad deportiva es representada, o se autorrepresenta, como modelo del nuevo ideal de individuo y de cuerpo.
\end{abstract}

Palabras clave: Running; consumo; estilo de vida; identidad

Abstract

The advances achieved by the feminist movement since the 1970 s have also been reflected in athletics, evidenced by exponential growth in women's participation, and by the reconfiguration of the new ideals about the female body, still in a continuous tension between the hegemonic stereotypes of the modern and attractive body constructed by western society. Although running is related to an introspective and individual practice of liberation, important brands and sport industries promote their products linked to a runner esthetic and identity utilizing specific "models," known as influencers or "ambassadors." The objective of this article is to analyze the representations which are constructed in running, with a focus on the participation of women in this sport, understanding that the body is a central element and that the market occupies a fundamental role in determining the "necessities" linked to consumption. To this end, I will reflect on my own fieldwork and analyze a series of advertisements, videos, and images on social media (specifically Instagram and YouTube) in which sporting activities are represented, or self-represented, as models of the new ideal of the individual and the body.

Keywords: Running; consumption; lifestyles; identity

1 Universidad de Buenos Aires. Facultad de Ciencias Sociales. Instituto de Investigaciones Gino Germani (iigg) y Conicet, Buenos Aires (Argentina). Correo electrónico: nemesiahijos@gmail.com. 


\section{Resumo}

A abertura alcançada pelo movimento feminista permitiu não só o crescimento da participação feminina em espaços antes proibidos, mas também uma reconfiguração dos ideais do corpo feminino, que continuam em tensão com os estereótipos hegemônicos do corpo moderno e atrativo. Apesar do fato de a corrida estar associada a uma prática de libertação e encontro individual, as grandes marcas e indústrias esportivas são responsáveis por reproduzir certas imagens coletivas através de influenciadores e "embaixadores" que dão conselhos nas redes sociais sobre o consumo de certas produtos associados a uma estética de identidade e corredor. 0 objetivo deste trabalho é analisar as representações construídas a partir da corrida, atentando para a participação das mulheres nessa prática, sabendo que o corpo é seu elemento central e que o mercado tem um lugar fundamental para orientar as necessidades. Para fazer isso, vou refletir sobre minhas observações de campo e vou analisar uma série de publicidade, vídeos e imagens em redes sociais (particularmente Instagram e YouTube), onde esta atividade esportiva é representada, ou auto-representada, como um modelo do novo ideal de indivíduo e corpo.

Palavras chave: Correndo; consumo; estilo de vida; identidade

Fecha de recepción: 30 de diciembre de 2017

Fecha de aprobación: 10 de septiembre de 2018

\section{Para citar este artículo}

Hijós, N. (2018). Influencers, mujeres y running: algunas consideraciones para entender los nuevos consumos deportivos y los estilos de vida saludable. Lúdica Pedagógica, 27, x-xx. 


\section{INTRODUCCIÓN²}

A grandes rasgos, el deporte sirve como constructor social y promotor de cualidades esenciales de la masculinidad hegemónica incluyendo la agresión, la fuerza, la competencia y, a veces, la violencia. Desde los años setenta, la explosión de movimientos de emancipación y liberación femeninos en casi todas las sociedades industriales ha llevado a una reconfiguración del lugar de las mujeres. El relato del empoderamiento femenino, materializado en hechos como la apertura a su participación en el mundo del trabajo y de la política, no se ha excluido de la esfera deportiva.

El desafío de este trabajo es analizar las representaciones que algunas deportistas construyen en el ejercicio del running ${ }^{3}$, una práctica que ha llegado a niveles sin precedentes de participación y visibilidad en Argentina -al igual que en el resto del mundo-, cuyo elemento central es el cuerpo. Para observar estas intersecciones de género, consumo y clase en el deporte argentino, utilizaré mis registros de campo y las entrevistas realizadas a un conjunto de interlocutores seleccionados ${ }^{4}$, acompañados de una serie de publicidades, imágenes y videos publicados en las redes sociales.

\section{TODAS PODEMOS CORRER, PERO}

\section{SOLO ALGUNAS HARÁN RUNNING}

Durante mucho tiempo y antes de que el running fuera un fenómeno en auge, correr era una disciplina específica del atletismo o parte del entrenamiento de

2 Una versión preliminar de este trabajo se presentó como ponencia en las III Jornadas Interdisciplinarias de Jóvenes Investigadores en Ciencias Sociales, organizadas por el Instituto de Altos Estudios Sociales (Idaes) de la Universidad de San Martín (Unsam) y realizadas en la ciudad de San Martín, Buenos Aires, Argentina, en septiembre de 2017. Agradezco los comentarios y aportes realizados por la licenciada María Florencia Blanco Esmoris.

3 La cursiva en el cuerpo del texto debe entenderse como una apropiación del discurso de mis interlocutores, términos significativos desde el punto de vista nativo y expresiones de los actores; también la utilizo para resaltar palabras en otro idioma.

4 Mis observaciones de campo comenzaron en abril de 2016 en el Nike+ Run Club (NRC) de Buenos Aires, el running team auspiciado por la marca internacional en más de cuarenta ciudades del mundo. Desde el inicio de mi investigación, enmarcada en el proyecto UвАсут 2016-2018 "Deporte, cuerpo y técnicas corporales: etnografía sobre CrossFit, running y boxeo en la Ciudad Autónoma de Buenos Aires" y en diálogo con mi proyecto de beca doctoral Conicet, comencé a participar como corredora amateur, entre tres y cuatro veces por semana, en las sesiones de entrenamiento grupales y -cuando me invitanen los eventos especiales organizados por Nike en la ciudad. otros deportistas. Este escenario de masificación de la práctica ocurre en conjunto con la aparición de lo que podría ser un "individuo pragmático", como modo de individuación propio de la época neoliberal (Rubinich, 2011), donde las personas toman parte en la cultura del rendimiento y en el relato de la autosuperación constante, de ponerse a prueba repetidamente todo el tiempo, entrenando tal vez sin una meta precisa en el horizonte pero con la obligación moral de tener que hacerlo a diario (Rodríguez, 2016). Así, el running constituye la mejor plataforma de operaciones para este tipo de individuos que buscan probarse a sí mismos todo el tiempo, entre los cuales especialmente las mujeres experimentan un creciente sentido de autorrealización y autoestima que se traduce en autonomía y confianza para los distintos ámbitos de su vida. Analizar la práctica del running, entonces, resulta una excusa para indagar, por ejemplo, los nuevos tipos de individualismo en la sociedad actual, pero también nos permite pensar cómo se gestiona el tiempo libre en estos nuevos procesos de individuación. Enmarcados en una sociedad de masas donde todo puede ser objeto de consumo, las actividades deportivas se reconfiguran, se profesionalizan, se espectacularizan, se patrocinan y se pagan. Por ello, en el mundo capitalista en el que vivimos, el correr no debe limitarse a una práctica de tiempo libre pasivo, porque esto implicaría que lo leyéramos como "tiempo estéril" (Castilla y Díaz, 1988 citado por Rodríguez Díaz, 2005, p. 1), de acuerdo con algunas perspectivas económicas, es decir, un tiempo que no implica gastos por lo cual es improductivo para el mercado. Como sabemos que la lógica del capital, de la racionalidad y del trabajo también está presente en las actividades físicas, el running se debe configurar entonces como una práctica de placer recreativo y ocio activo, sobreentendida cada vez más como un ejercicio de compra de bienes y servicios que vitalizan la economía, un ejemplo que sirve para demostrar que buscamos tensión y emoción en nuestro tiempo libre ${ }^{5}$.

5 Estas formas de vivir el deporte y el tiempo libre pueden vincularse con los planteos de Stebbins (1997) sobre el "ocio serio", expresión satisfactoria y substancial de ocio como actividad amateur, afición o voluntariado que comporta "una autorrealización profunda" (p. 17). 
A diferencia del atletismo, que es minoritario, la práctica del running atrae a individuos de edades, sexos y condiciones socioeconómicas diversas, que se congregan en ciudades para entrenar y planificar sus competencias en torno a grupos organizados por clubes, gimnasios, marcas, ex atletas o entrenadores amateurs, con un espíritu que promueve — desde un discurso particular - la inclusión y participación de todos. "Sentir el placer de correr" suele ser una de las razones principales expuestas por los runners para explicar su participación en las carreras populares. Esta razón, que pertenece a la categoría motivacional denominada satisfacción, está muy entremezclada con la libertad que experimentan al correr y con los beneficios que produce este deporte, particularmente en el cuerpo, como mencionan algunos participantes del grupo al que asisto. De todos modos, es necesario enfatizar la influencia que tiene sobre la decisión de participar en carreras el hecho de pertenecer a un equipo y de contar con entrenadores, coaches (en español, "instructores") y pacers ("liebres") ${ }^{6}$ que dirijan y planifiquen los entrenamientos, y que establezcan de forma directa o indirecta, implícita o explícita, lo que necesitan los corredores para participar de esta disciplina. Es decir, las mediaciones entre "lo poco que se necesita para salir a correr" y lo que se le impone y pauta desde fuera para ser runner. Así, las industrias deportivas, que identifican aquellos mercados sin desarrollar en su totalidad, le apuestan al potencial del running como disciplina.

Las mujeres no siempre han tenido el lugar protagónico que tienen hoy en el running. El hecho de que no hubiera incorporación de las categorías femeninas en los Juegos Olímpicos se argumentaba desde la presumible inferioridad física y la debilidad, un fenómeno que se materializaba en la invisibilidad atribuida al género femenino, tan arraigada en los siglos pasados que no daba lugar al debate sobre la igualdad de condiciones. De hecho, el llamado padre de los Juegos Olímpicos, el francés Pierre de Coubertin, sostenía (en 1912) lo siguiente acerca de la participación de las mujeres:

6 Los pacers son los encargados de marcar un ritmo determinado en carreras de media o larga distancia, o "pasadas" de velocidad. Estos corredores experimentados fungen como GPS, a los cuales se puede seguir sabiendo que se llegará a la meta con el objetivo de marca (tiempo y velocidad) planificado.
Quizás las mujeres se darán cuenta, rápidamente, de que esta tentativa no beneficia a su encanto ni a su salud, sin embargo, lo que sí tiene interés es que la esposa participe con amplitud en los placeres deportivos de su marido, incluso que dirija de forma inteligente la educación deportiva de sus hijos. Una olimpiada femenina sería impracticable, inestética e incorrecta. (p. 1).

El lugar de la mujer, entonces, era de acompañante del hombre, tal como en otras esferas de la vida. Y ante declaraciones como estas, es más factible imaginar el largo y duro camino que han tenido que recorrer las deportistas desde los siglos pasados con el objetivo de reivindicar, a través del esfuerzo y la lucha, las desigualdades de géneros en algunas modalidades. De hecho, hasta 1972 las mujeres no podían inscribirse oficialmente en eventos deportivos como las maratones ${ }^{7}$. No obstante, se presentaron hechos célebres, como la participación de Roberta Gibb, la primera mujer que corrió una maratón (en 1966) y lo hizo durante tres años consecutivos en esta misma prueba en Boston (Estados Unidos), o la más conocida Katherine Switzer, quien se inscribió con sus iniciales a través de un club de atletismo, pero a pesar de haber sido rodeada de sus compañeros para evitar que la vieran fue descubierta y perseguida por el director de la competencia quien le gritaba que saliera de su carrera. Estos episodios sentaron las bases para reflexionar acerca de que los argumentos biologicistas de exclusión de las mujeres de las carreras de resistencia no tenían fundamento. Hoy, las actividades deportivas en las sociedades contemporáneas demuestran que cuando las potencialidades físicas de varones y mujeres se activan al máximo mediante formas apropiadas de entrenamiento, extendidas a grandes masas de individuos de ambos sexos, las diferencias entre unos y otros son mínimas -en las carreras de distancias medias y largas se traducen en escasos segundos y en pocos metros en el lanzamiento de disco, bala o jabalina.

7 En el caso del atletismo, que debutó como deporte olímpico en categoría masculina en Atenas 1896, las mujeres solo pudieron participar a partir de Ámsterdam 1928 y únicamente en las pruebas de 100 metros, 800 metros llanos (que fue suspendida hasta Roma 1960 por el Comité Olímpico Internacional ante las presiones presentadas en contra de la participación de la mujer en este tipo de competencias, aludiendo a su extenuación), $4 \times 100$, salto de altura y lanzamiento de disco. Cabe destacar que una de las pruebas más significativas, la maratón, solo tuvo categoría femenina a partir de Los Ángeles 1984. 
El "ingreso" de las mujeres sobre todo a deportes tradicionalmente considerados "de varones" desafía esta construcción social de género y las lleva a enfrentarse no solo con obstáculos institucionales, socioculturales y económicos, sino también con marginalización y estigmatización social. Por otro lado, los deportes "femeninos", clasificados así porque las mujeres componen la gran mayoría de los participantes, tienden a reforzar ideales femeninos hegemónicos, enfatizando la belleza, la gracia y la cooperación. Sylvia Burrow (2016) se refiere a las dificultades de las deportistas como una situación sin salida, ya que las mujeres que quieren participar en deportes femeninos se sujetan a una devaluación irreversible por prejuicios y sesgos, mientras que las deportistas que desean entrar a disciplinas tradicionalmente masculinas se enfrentan con la posibilidad de marginalización y estigmatización -aunque Burrow no menciona a las practicantes de deportes "neutros"8 como el running, se supone que ellas deben afrontar un dilema parecido-. Según las estadísticas elaboradas por las empresas organizadoras de carreras, hace más de una década solo el $5 \%$ de las mujeres corría, mientras que hoy el porcentaje alcanzaría el $49 \%$.

La atleta olímpica argentina Marita Peralta ${ }^{9}$ ha relatado que en los inicios de su carrera, hace alrededor de treinta años, no tenía otra opción que usar ropa de hombre para salir a correr. Mientras que antes se corría con ropa de algodón y zapatillas básicas, actualmente se le atribuye a la indumentaria y al calzado una cuota de responsabilidad en el rendimiento de las deportistas: "La ropa de aquella época casi que no nos incluía. Por suerte eso ya pasó y hay tantas mujeres como hombres en las carreras. 0 , mejor dicho, nos estamos acercando a la mitad" (Cáceres,

8 En deportes "neutros" como el running o el tenis, las deportistas son representadas como participantes de una versión "menor" o secundaria a la competencia masculina. En el atletismo, los varones siempre corren en último lugar, sus competencias son los eventos centrales y más publicitados (por ejemplo, en los 100 metros masculino versus los 100 metros femenino, Usain Bolt recibía mayor atención que la ganadora femenina). Y en el tenis ocurre algo similar: en los torneos importantes, las mujeres juegan la final un día antes y compiten con el cubrimiento de las finales del campeonato de dobles, mientras que la final masculina se hace el último domingo y es el evento principal del torneo. Además, en los majors, mientras que los varones juegan hasta cinco sets, las mujeres participan hasta en tres porque se les atribuye una limitación física.

9 A excepción de las personas públicamente reconocidas, los nombres de los interlocutores en el trabajo de campo se han modificado a fin de resguardar su anonimato.
2015). Habiendo superado esa etapa donde también el mercado las ignoraba, hoy la indumentaria y el calzado resultan una forma de expresión y de estética para las mujeres deportistas, quienes materializan su estilo a partir de la elección de los modelos de calzas o remeras. Es así que gran parte de las corredoras considera importante, aparte de seguir una rutina de entrenamiento, estar al tanto de las novedades y las tendencias en moda deportiva o tener algún complemento tecnológico de última moda. A pesar del reconocimiento popular que ha adquirido la figura de Peralta como representante femenina en los dos últimos Juegos Olímpicos en distancias largas, su imagen en los medios de comunicación suele estar construida a partir de las referencias sobre su rol de esposa y madre. Tal vez por haber superado los cuarenta años de edad o por su perfil exclusivamente asociado al rendimiento deportivo, ni los medios ni las marcas eligen exhibirla como una "bomba" del running, sino como una "mamá maratón". Su contracara, partiendo de la forma como se representa a las mujeres vinculadas al running y al atletismo, podría ser la joven marplatense Sofía Luna, sobre la que nos detendremos más adelante.

A diferencia de la prohibición que se mantenía antes de los setenta, en la actualidad no se puede pensar en el lanzamiento u organización de una carrera sin la participación de las mujeres, en particular, por la red de consumos que generan y por el grado de protagonismo que tienen en las redes sociales. De hecho, hay competencias exclusivas para mujeres, las cuales se iniciaron con la finalidad de demostrar que las largas distancias no eran solo para los varones, además de servir como una prueba concreta de que también podían correr. Las empresas que organizan estos eventos argumentan que, si bien puede parecer sectario, no lo es, porque el objetivo no es aislar al género femenino, sino integrarlo a un mundo anteriormente pensado para varones. La creciente participación de mujeres en competencias de resistencia se traduce como una habilitación y legitimidad en la práctica deportiva, que se relaciona con sus intereses estéticos vinculados a la transformación del cuerpo y a la ampliación de los vínculos de sociabilidad. El género no es el único factor determinante del éxito o desprecio de un deporte o un deportista, ya que en la construcción del imaginario deportivo también influye la clase social, ligada al nivel socioeconómico 
materializado en el estilo de vida y en el consumo. En la medida en que las personas deben reinterpretar y reorganizar los bienes y servicios que adquieren en función de un estilo propio que están construyendo, el consumo se configura como un acto voluntario y creativo (Sassatelli, 2012). Sin embargo, esto no implica que sea un acto totalmente racional y libre, ni tampoco un acto de soberanía y dominio sobre el mundo y las cosas.

\section{LAS MARCAS EN EL RUNNING}

En 2016, en el marco de mi trabajo de campo etnográfico, asistí a tres eventos especiales para corredores amateurs y usuarios de la plataforma de entrenamiento Nike+ Run Club (NRC) organizados por la empresa Nike en Buenos Aires. El primer evento en el que participé - lo que podría ser mi acercamiento al campo- fue una sesión de running exclusiva para mujeres llamada "Vení a correr con nosotras", inspirada en el lema del empoderamiento femenino y enmarcada en el Nike Women Victory Tour (Tour de la Victoria de las Mujeres), una serie de medias maratones exclusivas que la firma organizó de marzo a septiembre en distintos países ${ }^{10}$. Me había enterado de esta actividad a través de una publicación de Sofía Luna en Instagram. Sofía es una joven atleta oriunda de la ciudad de Mar del Plata, anunciada en algunos medios como "la promesa del running". Aunque aún no ha representado al país en ningún juego olímpico, debido a su belleza y a su cuerpo proporcionalmente tonificado, de acuerdo con los parámetros considerados aceptables, distintas marcas la convocan para realizar campañas de indumentaria urbana que realzan su sensualidad, más allá de su condición de atleta Nike. La lectura de las imágenes y posteos en las redes sociales de Luna (con más de 52000 segui-

10 Según la página oficial, el objetivo del Nike Women Victory Tour es inspirar y motivar a más atletas en la serie de eventos más grande para las mujeres, para que superen sus límites, alcancen sus metas, conectándose y formando parte de la "comunidad Nike+". El lema de la carrera, "Join the journey and show the world your wings" (Únete al viaje y muéstrale al mundo tus alas"), presenta una metáfora entre la liberación femenina y el hecho de tener alas, y realza el repertorio de autosuperación en un contexto donde el ejercicio (en términos de moralidad) actúa como una marca de diferenciación (el hecho de "sacar lo mejor de uno mismo", para ponerlo a prueba y ser mejor). dores en Instagram: @sofilu20) ${ }^{11}$, lleva a pensar en ella como modelo y "IT girl"12 antes que deportista.

Esta sesión de entrenamiento que publicitaba Sofía tuvo lugar un sábado de abril en el Parque de los Niños (en la zona norte de Buenos Aires) y comprendía correr 10 kilómetros, acompañadas por distintos pacers que marcaban el recorrido y ritmo de la carrera. Al finalizar, se brindó un servicio de brunch ${ }^{13}$ con comida y bebida saludable, y se guio un estiramiento focalizado mientras desde el escenario un DJ pasaba música dance y los coaches hacían anuncios sobre el funcionamiento de NRC. Cuando retiré mis pertenencias del guardarropa, los jóvenes del personal me indicaron que Nike iba a continuar con esta serie de eventos especiales a lo largo del año como una modalidad divertida, festiva, entre amigos, pero con un entrenamiento exigente y de calidad, para acompañar el proceso de preparación de lo que iba a ser la primera media maratón exclusiva para mujeres organizada por la marca en Buenos Aires. Si bien pensé que iba a encontrarme con la atleta marplatense, los chicos me dijeron que no había ido pero que estaba promocionando el evento para que más chicas pudieran animarse y así entrenar para correr los 21 kilómetros. Dejé mis datos de contacto, el día lunes recibí las fotos del evento en mi correo electrónico y la siguiente semana pude inscribirme en las sesiones de entrenamiento ${ }^{14}$.

Ya como parte del grupo y asistiendo regularmente a las actividades organizadas por la marca, el siguiente evento en el que participé fue una sesión especial del Nike Training Club (NTC) ${ }^{15}$, también exclusiva para

11 Los datos que se mencionan fueron relevados en septiembre de 2018.

12 Las "Iт girls" son mujeres jóvenes a las cuales se les atribuye un poder de atracción y actitud. Haciendo uso de los espacios digitales, comparten sus experiencias a través de imágenes: su amor por la moda, los viajes, la fotografía y otros rubros, sugiriendo consideraciones estéticas y preceptos morales.

13 Brunch es un acrónimo a partir de la unión de breakfast (en español, desayuno) y lunch (almuerzo).

14 Durante 2016 el entrenamiento estaba pautado en cuatro sesiones semanales: lunes de Ready, Set, Go, Run (para correr mejor), miércoles de Speed Run (para ser más fuertes y rápidos, con trabajos de velocidad y pasadas en una pista de atletismo o sobre la vereda de una avenida), jueves de Home Run (un día de diversión, de correr con amigos y hacer otros nuevos) y sábados de Long Run (para correr 8, 12 o 18 km en circuitos turísticos por la ciudad y ayudar a los que estén preparando objetivos especiales).

15 Buscando explotar su potencial de atleta, la marca desarrolló planes de entrenamiento y ofertó dos sesiones semanales de functional training (entrenamiento funcional) exclusivas para 
mujeres, en un distinguido salón cercano a la costanera de Buenos Aires. Ese día no solo hubo una intensa clase de entrenamiento funcional y baile aeróbico coordinado, sino también un selecto catering y música chill-out al final del ejercicio. Al ingresar, nos invitaban a dejar las pertenencias en el guardarropa y antes de empezar el entrenamiento en una sala ambientada, los chicos del personal nos ofrecían probar durante la sesión las nuevas zapatillas diseñadas exclusivamente para functional training. Entre el público (con más juventud que en el evento anterior) estaba la joven cantante, actriz y modelo Oriana Sabatini, quien entrenó a la par de nosotras y luego se dedicó a modelar para el fotógrafo de Nike y a sacarse selfies con quienes le pedían.

Muchos corredores del grupo me dijeron que uno de los mejores eventos es el cierre anual, ya que NRC funciona durante el ciclo lectivo (de marzo a diciembre) y hace un receso en el verano, asumiendo que la mayoría de sus participantes pasan vacaciones fuera de la ciudad. A fines de diciembre fuimos invitados a registrarnos en un entrenamiento especial en el Centro Nacional de Alto Rendimiento Deportivo (Cenard), al que asistieron reconocidos atletas olímpicos asociados a la marca ${ }^{16}, \mathrm{y}$ nos guiaron con instrucciones durante los ejercicios. El entrenamiento no era lo más esperado de aquel día. La atención de los participantes estaba puesta en cuáles iban a ser las sorpresas y qué iba a ocurrir cuando completáramos las pasadas de velocidad en la pista de atletismo. Al terminar la sesión se ofrecieron tentadoras opciones de entrada dispuestas en islas temáticas y repartidas por mozos, aunque sin bebidas alcohólicas a diferencia del cierre de 2015. El ambiente deportivo desencajó completamente cuando empezó a sonar

mujeres, bajo el eslogan "Vení a entrenar con nosotras". La mayoría de mis interlocutoras son mujeres de 20-40 años que están retomando la actividad física, lo cual sirve para pensar en los imperativos que circulan sobre la práctica deportiva en estos grupos etarios. Nike lo tiene en cuenta y adapta el entrenamiento: no es tan intenso como las sesiones de running, sino complementario, como si correr fuera lo principal, lo que marca el objetivo a largo plazo.

16 Participaron varios atletas Nike de Argentina: las corredoras Sofía Luna, Belén Casetta y Fiorella Chiappe, la yudoca olímpica Paula Pareto, el corredor Luis Molina y jugadoras de Las Leonas, acompañados de figuras con incidencia en el running como el periodista Daniel Arcucci y la bloguera Marou Rivero. cumbia y música "de joda"17, se armó el trencito al lado de la pista de atletismo y se bailó al aire libre hasta pasadas las 23 horas. Coaches y pacers repartían accesorios de cotillón: anteojos, gorros, corbatas fluorescentes, collares luminosos y viñetas con frases asociadas a Nike: "Puedo más", "Just Do It", "NRC Bue”, con las que los runners posaban para el fotógrafo $\mathrm{y}$ para transmisiones en vivo desde sus celulares.

El año 2017 comenzó siendo aún más exclusivo y perfilado al trabajo con influidores y embajadores de la marca. Con la excusa planificada de celebrar los treinta años de las zapatillas Nike Air Max, la empresa decidió desglosar el festejo en cuatro encuentros especiales que representaban enfoques característicos del producto: revolución, ícono, colaboración e innovación. Todos los sábados de marzo se realizaron eventos en el local de Nike en Palermo Soho, acompañados de lanzamientos de las ediciones limitadas de este modelo de zapatillas. En el primero, dos de los invitados hicieron una "curaduría de la moda" en vivo, haciendo recomendaciones personalizadas sobre cómo combinar de forma correcta un outfit urbano con los pares de las "infaltables" Air Max para completar el look. Dentro del local relucían modos de vestir que se pueden pensar como extravagantes para el ámbito del deporte pero que están asociados a signos de distinción social: prendas como tapados de piel, sombreros, chaquetas con brillos, anteojos de sol, polleras escocesas, tanto para mujeres como para varones, que -fusionados con zapatillas deportivasimponen la tendencia athleisure ${ }^{18}$, en búsqueda de la

17 Si bien la cumbia se asocia como "la música de los pobres", su amplia difusión (a través de la mediación de las industrias culturales) la llevó a consagrarse como el género más popular, en su doble sentido de consumo y significación de clase. En la actualidad no solo suena en fiestas como símbolo de "joda", sino que convoca a jóvenes de clases medias en boliches de Palermo y los impulsa como artistas que vuelven a hacer versiones clásicas de la música en formato de cumbia cool (conocida como "cumbia pop/cheta"). Silba (2017) las Ilama "cumbias blanqueadas": entran en el consumo de las clases medias, quienes pueden bailarlas sin temor a que se les filtren prácticas culturales demasiado plebeyas para ser toleradas. El hecho de que las clases medias encuentren diversión, placer, alegría o emoción a través de sus experiencias con esta música nos permiten entender los fenómenos de "plebeyización" cultural ocurridos en las últimas dos décadas (Alabarces y Silba, 2014; Silba, 2015).

18 Athleisure fusiona las palabras athletic (en español, "atlético") y leisure ("ocio"), y supone una nueva manera de mezclar atuendos que antes resultaban imposibles (como conjuntos deportivos con botas de taco aguja o pantalones de vestir con zapatillas de running) pero también ligados a diseños 
comodidad. Afuera del comercio y desde horas muy tempranas, jóvenes, y otros no tanto, hacían largas filas para reservar y comprar las ediciones limitadas.

Los cuatro eventos fueron promocionados a través de la campaña digital \#AirMaxDay lanzada globalmente en plataformas como Instagram, Facebook y Twitter, pero buscando un particular impacto y visibilidad urbana con espíritu de celebración en las ciudades más destacadas. En Buenos Aires se convocó a celebridades e influidores asociados a la marca (como la actriz, modelo, DJ y corredora aficionada Calu Rivero, y el DJ Tommy Muñoz), pero también se invitó a algunos corredores de NRC a participar del festejo haciendo ruido por las calles de Palermo, paseando por fuera de los bares cercanos al local de Nike Soho, luciendo cotillón luminoso, usando silbatos y megáfonos que despertaran curiosidad de quienes transitaban por la zona. Aquellos miembros de NRC que tenían (o habían comprado) calzado Air Max, hicieron una sesión de fotos especiales, las cuales fueron reposteadas por la marca en las redes. Eventos como estos, sumados a las sesiones de entrenamiento de NRC, responden a la imagen que fomenta y quiere instalar la marca: asociarse a consumos considerados distinguidos, alejados de las prácticas construidas socialmente como vulgares (Bourdieu, 2012). No es casual que Nike denomine sus actividades como especiales, porque desde la semiótica y la práctica reflejan el resultado de estrategias de diferenciación y de un ejercicio de gusto orientado por el rechazo a la vulgaridad inherente a las personas "comunes". El beneficio de distinción, dice Bourdieu, es el beneficio que otorga la diferencia, la separación que aparta de lo común, que tiende a legitimar ciertos objetos y comportamientos, y marginalizar consecuentemente otros. Esta clasificación de lo distinguido y lo vulgar no es natural ni proviene de una subjetividad refinada, sino que son construcciones sociales realizadas por los grupos dominantes en su lucha por imponer, frente a otros grupos, visiones del mundo que sustenten y den sentido, al mismo tiempo que reproduzcan, una realidad que los mantenga en la posición de poder. Entonces, como el gusto es una construcción social legitimada por los grupos dominantes de cada época

exclusivos, líneas de lujo y materiales de alta calidad. Esta tendencia busca imponerse para toda ocasión: día, noche, ámbito diario, laboral y profesional. y cultura, aquello que vamos a preferir consumir va a ser el resultado de una jerarquización de variables por las que nos diferenciamos: capital social, cultural, económico, además de género, edad, profesión. Marcas como Nike saben captar ese "quiénes somos", nos interpelan para hacernos sentir parte a través de consumos y prácticas, y generan identidad, para vendernos más.

Los eventos especiales son una expresión de distinción que crea un ambiente cargado de emociones en el cual la empresa no regatea en el esquema de producción. La celebración del aniversario de las Air Max buscó transformar las calles de Palermo instalando estaciones dedicadas a revolucionar los estilos a través de "sneakers services", donde los presentes podían intervenir sus zapatillas, hacerse nail art, aprovechar el servicio de barbería para recortarse la barba y el pelo, y ver colaboraciones artísticas de tatuadores y estilistas. Más allá de las celebridades que se lucieron en el escenario en pleno paseo urbano, y los influidores y embajadores que participaron, NRC invitó a algunos corredores a ser parte del \#AirMaxDay. Nike nunca dejó en claro cuáles fueron los criterios de selección por los cuales convocó a algunos en lugar de otros, por lo que esta decisión no solo trajo enojo y especulación entre los miembros de NRC, sino que comenzó a entronizar a corredores anónimos como verdaderos protagonistas. La marca programó sus actividades sumando rostros desconocidos de una serie de jóvenes deportistas amateurs dispuestos a arengar en momentos de euforia y a replicar sus campañas en las redes sociales, no solo porque estos consumos se corresponden con lo valorado socialmente sino también porque sirven como una especie de trampolín profesional y de reconocimiento. Estas decisiones resultan rentables para empresas como Nike, que destinan menos recursos a campañas gráficas y se posicionan (con product placement) a través de réplicas en las redes sociales de "gente común" que aspira a conseguir productos o transformarse en personalidades asociadas a la marca.

En los festejos por los treinta años de las zapatillas, mientras disfrutábamos del espectáculo de cierre a cargo de la cantante Miss Bolivia, Lucrecia me dice: "Pensar que casi no vengo, lo que me iba a perder.. me enteré de casualidad en el Home Run". Me sorprende su comentario. Ella fue una de las corredoras 
que participó del NRC Pace Camp ${ }^{19}$, con un fuerte compromiso hacia las actividades organizadas por Nike. Aunque sólo había faltado a algunos entrenamientos, ahora no la tenían en cuenta como antes, haciendo alusión al periodo inmediato al viaje a Chile, cuando era muy popular en el grupo, reconocida entre los demás corredores y con más de mil seguidores en Instagram. Con el deseo de mejorar su rendimiento deportivo y planificar mejor sus competencias, hacía algunos meses que Lucrecia estaba entrenando en el running team dirigido por el ex atleta olímpico Luis Migueles. No era la única participante del NRC que iba con otro grupo, no obstante, sí era la única que había viajado con Nike a Chile y que estaba yendo a entrenar a otro lugar. Parecería ser que los que toman decisiones en Nike Argentina redefinen las lealtades en términos de reciprocidad, valorando quiénes asisten al NRC, con qué frecuencia, qué postean en sus redes sociales, cómo interactúan con la marca, además de qué indumentaria y calzado lucen.

Ante la oferta y el despliegue montado por Nike, los participantes terminan naturalizando prácticas que no son las que circulan usualmente en cualquier ámbito deportivo. El entrenamiento con NRC se puede pensar como ejemplo de "business ético", un fenómeno ambivalente tanto para los consumidores como para los productores, en el cual la empresa estaría impulsando concientización sobre un "estilo de vida saludable" y promoviendo la actividad física a través de su grupo de running "gratuito" ${ }^{20}$. Pero no debemos desconocer que lo que priman aquí son los vínculos de reciprocidad y la configuración de lealtades

19 El NRC Pace Camp fue una experiencia organizada por Nike en 2016 que convocó a asiduos corredores del NRC. "especialistas" en running, periodistas e influidores, para correr durante cuatro días en Chile, participar de charlas técnicas y probar nuevos productos. Los organizadores nunca explicaron los criterios de selección sobre los que se fundaron. Este hecho desató asperezas, controversias y especulaciones entre los integrantes del grupo, quienes continúan haciendo conjeturas sobre cómo ser considerados por los coaches, poniendo en funcionamiento una serie de tácticas y estrategias para que los tengan en cuenta.

20 Si bien la práctica deportiva supervisada por profesionales contratados por Nike no es arancelada, esto no significa que no exista un tipo de contrato tácito o inconsciente que lleve a los sujetos a realizar algo a cambio, en calidad de tributo o fidelidad a la marca. Son estos mismos corredores amateurs los que realizan publicidad luciendo indumentaria o calzado Nike, utilizando la aplicación para dispositivos móviles y operando como propagadores de la marca a partir de la superexposición que hacen en las redes sociales mencionando o aludiendo a la empresa. entre coaches, pacers y corredores amateurs. Aunque en sus diálogos cara a cara y en las interacciones a través de las redes sociales los participantes se muestran conscientes al reconocer tanto los peligros como los beneficios de entrenar en el running team de una marca internacional, en sus prácticas se expresan sentidos contradictorios: de acuerdo con sus posibilidades, consumen (o se esfuerzan por comprar) indumentaria y calzado Nike, y cuando no pueden acceder a dichos bienes o no se sienten tenidos en cuenta por NRC, recurren a otras estrategias como lucir ropa "trucha" (de imitación) o productos del principal competidor (Adidas). En primer lugar, estas acciones se pueden leer como formas de implementar lo que Bourdieu (2012) llama "sustitutivos en rebaja" o, en el segundo caso, como formas de resistencia frente al anhelo de fidelidad que pretende la marca.

\section{EL ROL DE LAS REDES SOCIALES}

Guiándonos por publicidades, fotografías y videos en las redes sociales de mujeres practicando deportes, las clásicas representaciones y descripciones pondrían en primer lugar sus figuras y atributos ligados a la apariencia física, sin reforzar tanto sus habilidades y logros deportivos (Garton e Hijós, 2017; 2018). De la mano de estas tradicionales imágenes, en general las deportistas reciben menos espacios en los medios masivos de comunicación, tanto impresos como televisivos, que sus contrapartes varoniles (Cooky, Messner y Musto, 2015; Aráoz Ortiz y Moreira, 2016). Asimismo, por un lado, estas coberturas frecuentemente resaltan la belleza y sensualidad de las mujeres que responden a una femineidad hegemónica correspondiente a la idea de que deben ser jóvenes, delgadas, bellas y sensuales, y refuerza la posición histórica y culturalmente creada como "objeto de deseo y la mirada masculina". Otras coberturas destacan la relación complementaria que tienen como novias, esposas, amantes, madres, hermanas o hijas de deportistas reconocidos. Como plantea Calvo Ortega para el caso de la televisión española, es de destacar el "gran espacio que ocupa la mujer no deportista en la mayoría de los canales llegando a sobrepasar con creces o en su totalidad el espacio de la mujer deportista" (2014, p. 122). Por otro lado, otras coberturas trivializan las capacidades deportivas de las atletas a través de estrategias de "ambivalencia". Mediante imágenes o representaciones contradictorias, la ambivalencia 
intenta conciliar la incompatibilidad entre la femineidad y el mundo masculino del deporte (Cranmer, Brann y Bowman, 2014). En este sentido, con imágenes o videos buscarán ridiculizar los talentos deportivos de las atletas, en secciones catalogadas como "burradas", afirmando así el ideal de subalterno asignado históricamente a las mujeres respecto a la posición dominante de los varones. Además, si bien los medios de comunicación no hacen un seguimiento constante de sus carreras y competencias, cuando las mujeres no logran marcas trascendentales o reconocidas para su posición no son consideradas "sujetos noticiables" (Aráoz Ortiz y Moreira, 2016, p. 122).

Las transformaciones logradas por el movimiento feminista también tuvieron lugar en el deporte con altos niveles de crecimiento en la participación de mujeres. Esta apertura aportó nuevos ideales occidentales de un cuerpo femenino fuerte, deportista, independiente, y comenzó a desafiar el modelo victoriano de la mujer delgada y débil, pasiva y sumisa. Por ejemplo, a fines de los setenta y comienzos de los ochenta, junto con el avance del feminismo, el fútbol practicado por mujeres reaparece en Latinoamérica con una creciente aceptación y un mayor desarrollo, lo que permite superar algunas barreras en países donde este deporte particularmente ha sido construido como un espacio de hombres (Rial, 2013). El paso del tiempo marcó una nueva configuración sobre el cuerpo femenino: sin embargo, aunque estas nuevas concepciones del cuerpo "saludable" pero también "sexy" se inspiraron en una apertura importante del mundo deportivo a las mujeres, también fueron apropiadas y fomentadas por la lógica mercantil a través de publicidades, posteos en las redes sociales y por medio de ciertos referentes elegidos por las marcas que fortalecen estos discursos. Si bien sus mensajes instruyen sobre sobre el cuidado corporal y el "estilo de vida saludable" a través de consejos alimenticios y planes de entrenamiento físico, el deseo o la meta es "lograr el cuerpo perfecto" - no solo fuerte y deportivo sino también flaco y atractivo-. Es decir, la adopción de nuevos estilos de vida puede operar como la puerta de entrada hacia un "modo de vida más saludable", al involucrar el abandono de un conjunto de hábitos considerados negativos o perjudiciales como fumar, consumir grasas saturadas, carbohidratos en exceso o alimentos procesados, además de otras búsquedas como reducir el estrés cotidiano, reconfigurar relacio- nes personales, o vincularse con el medio ambiente, aunque el discurso problemático siga ligado a la búsqueda de la perfección estética y al consecuente movimiento para controlar el cuerpo femenino.

En un auge por el cambio hacia una "vida más saludable", la necesidad de transformar el físico suele ser pautada en las redes sociales por "los gurús del fitness" y deportistas profesionales, aunque también por "personas comunes" elegidas por las marcas. Estos "fitfluencers" se presentan como amigos que imparten consejos para seguir un estilo de vida que gira en torno al fitness, incitando el consumo de ciertos productos y actividades y a la vez fortaleciendo tendencias basadas en estereotipos hegemónicos del cuerpo moderno y atractivo. En el caso de Instagram, desde que fue comprada por Facebook, dio un giro en su funcionalidad. Además de haber incorporado espacios publicitarios pagos, resulta una "cantera de talentos" de personas que encuentran una herramienta para expresarse y generar un medio de vida. Con miles de seguidores, actualmente se denominan influidores y es lo que las empresas buscan como canales para llegar a los consumidores, pensando sus nombres como marca. Estos influidores son nativos digitales, que conocen las reglas de la (auto)exposición en internet, cuidan y planifican lo que suben, aunque los más profesionales tienen personas que los ayudan a gestionar el contenido. Pero a aquellos que buscan lo genuino y la expresión real en las redes sociales, les molesta ver que les venden algo. Agustina D’Andraia dice que "la clave es no caretearla", "yo no lucro, no gano dinero, pero logré inspirarme para escribir Diario de una chica fit (2015)" (Fernández, 2017). Conocida por su seudónimo "Agus Dandri” (@agusdandri en Instagram,con más de 212000 seguidores) fue la primera "fit girl" que marcó la llegada y la propagación de esta moda ligada al "cambio de cuerpo y cambio de vida" que fortalece el estereotipo del cuerpo moderno y atractivo. El cuerpo "fit" ya no es un cuerpo femenino débil, pero tampoco es el cuerpo del deportista masculino corpulento y hercúleo, sino un cuerpo musculoso, pero no demasiado, fuerte, pero a la vez esbelto -que se consigue quemando grasa y aumentando músculoligado a una moralidad superior por aprender a elegir y tomar buenas decisiones. Con un entorno que no la apoyaba, encontró en internet una comunidad global que compartía esta pasión y se hizo conocida. "Le cambió la vida", no solo por el notorio cambio físico, 
sino porque la volvió referente de un género que está en auge como a otros tantos influidores y embajadores, que se encontraron con la fama repentina y la exigencia de "vivir para las redes". En estas plataformas conviven ideas de autorrepresentación, donde las personas están expuestas a situaciones que antes solo el mundo del espectáculo vivía. A través de lo visual somos capaces de elegir qué estilo de vida deseamos llevar. Pero lo que se muestra -lo que mostramos- es una construcción que hacemos de nosotros, que se pone en tensión con la autenticidad que se relata. En definitiva, lo que se postea en las redes una construcción de nosotros mismos, atravesada por el mercado, donde se manipulan nuestros cuerpos y nuestra apariencia, juzgados por medio de la aprobación o ignorancia de los "Me gusta" de otros.

Naomi Klein (2015) dice que las marcas se han convertido en un lenguaje global y sostiene que las compañías multinacionales estarían cada vez menos interesadas en vender productos, sino que lo que ofrecen son modos de vida e imágenes. Así observa cómo en muchos casos la manufactura de mercancías con el nombre de famosas marcas, como Nike, son subcontratadas a otras compañías, mientras la corporación en sí se enfoca exclusivamente en el marketing de marca. El objetivo principal es asociar la compañía a una imagen de prestigio o de vida atractiva. En esta misma línea, el discurso del management empresarial afirma que hoy no basta con aparecer como patrocinador en una remera o en la estática de un espacio concurrido, porque las personas están buscando experiencias. Los ejecutivos ligados al marketing, la publicidad y la comercialización de productos y servicios sostienen como necesidad llevar lo profesional a la "gente común", utilizar los productos con un propósito motivacional para que las marcas puedan posicionarse. Estas propuestas hacen referencia a potenciar la industria a través del consumo, con las redes sociales como herramientas apropiadas (en ningún sentido alternativas) para que las marcas se involucren con el público. Este es uno de los puntos en los cuales se focalizó Nike para seguir expandiéndose como empresa deportiva líder en el mercado: organizando sesiones, celebraciones y eventos especiales, creando vínculos de lealtad con los corredores amateurs, generando comunidad entre ellos, invitándolos a correr con amigos, interpelándolos con mensajes evocadores en las redes sociales, para que elijan vivir la experiencia de entrenar con ellos.

La publicidad se presenta como un lenguaje particular, un modo de comunicar que es abiertamente persuasivo y que explota la posibilidad de asociaciones simbólicas inherentes a la comunicación verbal y visual. En el running, si bien las grandes marcas como Nike deben construir su público, logran fidelizarlo y fanatizarlo de manera similar a lo que ocurre, por ejemplo, con los clubes de fútbol: cuando reúnen el corpus de gente, interactúan con ellos, generan lazos, identificación y comunidad, y les permiten vivir experiencias que los hacen sentirse parte de, lo que los convierte en personas especiales, importantes. Es así que, una vez que Nike logra penetrar en el lugar que ocupa el deporte en sus vidas, puede tener runners fanáticos en vez de clientes. La apuesta de la marca se redobla al visibilizar a las mujeres en un espacio anteriormente considerado "de varones", incorporándolas a sus sesiones y desarrollando elementos "para la corredora", pero además generando la necesidad en ellas, lo que las predispone a creer que requieren tales productos para practicar el deporte. Asimismo, estos consumos que hacen a la práctica del running se ligan a determinados (y valorados) estilos de vida, van configurando determinados cuerpos, discursos y prácticas, al igual que desarrollan una estética hegemónica.

\section{REFLEXIONES FINALES}

El alcance y el éxito de un deporte obedece en muchos aspectos a la imagen que las grandes empresas, legitimadas por la lógica mercantil, proponen y construyen sobre esa práctica deportiva, orientada para una sociedad occidental de clase media. En el running hemos visto cómo, con el impulso de las nuevas tecnologías, se pueden estructurar ciertas representaciones y guiar determinados consumos donde las marcas (por medio de influidores, embajadores o "gente común") legitiman estereotipos de cuerpos, belleza y moda, y pautan lo que está bien y lo que está mal en términos morales. Sirviendo a los grandes poderes, buscan convencernos, persuadirnos y colonizar nuestras conciencias alrededor de una realidad virtual, instalando nuevas moralidades pero también falsedades que gran parte de la población cree verosímiles porque son difundidas por los medios masivos pero en particular porque las redes sociales (y 
nuestros grupos de pertenencia) replican e instalan aquellas realidades.

A pesar de los grandes cambios introducidos por los movimientos feministas, en las redes sociales se sigue percibiendo y reproduciendo hasta nuestros días la imagen de las mujeres como mero símbolo y mercancía (incluso ocurre que la versión sexualizada es autorrepresentación). Resulta así que las atletas que obtienen visibilidad o son elegidas por las marcas, no lo logran por su talento en el deporte sino por responder a parámetros de belleza hegemónica o su capacidad de engagement, por conseguir la atención de las personas. Podría pensarse que en el running la capacidad de agencia de las mujeres se manifiesta a través de la indumentaria, siendo la manera a través de la cual la deportista puede "expresar su libertad", aunque eligiendo dentro de los parámetros establecidos por las marcas (a partir de un juego entre oferta, demanda y marketing), o — de una forma más sutilsegún lo que sugieren los influidores y embajadores seleccionados por dichas empresas. En definitiva, ni el ámbito del running ni el rubro indumentaria dejan de ser espacios donde la expresión de libertad es ilusoria, ya que las elecciones no son totalmente autónomas sino que están sujetas a una serie de factores, jerarquías e influencias sociales, culturales y mercantiles. En un contexto de lucha por la autonomía de los cuerpos y el empoderamiento femenino, en un espacio que se supone democrático, como lo es el de las redes sociales, deberíamos preguntarnos cuán libres son realmente las mujeres. En lugar de mantener una actitud pasiva, nuestro próximo gran desafío deberá ser promover el uso de nuestras propias experiencias para entender las (nuevas) relaciones sociales y las disputas de sentidos en el funcionamiento del mundo.

\section{REFERENCIAS}

Alabarces, P. y Silba, M. (2014). "Las manos de todos los negros, arriba”: Género, etnia y clase en la cumbia argentina. Cultura y Representaciones Sociales, 8(16), 52-74.

Aráoz Ortiz, L. y Moreira, V. (2016). Prensa deportiva en Argentina. Construcciones identitarias y estilos discursivos del deporte en el diario Olé. Trama de la Comunicación, 20(2), 111-124.

Bourdieu, P. (2012) [1979]. La elección de lo necesario. En La distinción: criterio y bases sociales del gusto (pp. 441456). Madrid, España: Taurus.
Burrow, S. (2016). Trampled autonomy: Women, athleticism, and health. International Journal of Feminist Approaches to Bioethics, 9(2), 67-91.

Cáceres, D. (2015). "Informe: ellas y el running, mujeres que vuelan”, La Nación, 23 de abril.

Calvo Ortega, E. (2014). La representación de la mujer y los roles de género en los informativos deportivos de televisión. Fonseca, Journal of Communication, 8(8), 111-129.

Castilla, A. y Díaz, J. (1988). Ocio, trabajo y nuevas tecnologías. Madrid, España: Fundesco.

Cooky, C., Messner, M. A. y Musto, M. (2015). "It's dude time!": A quarter century of excluding women's sports in televised news and highlight shows. Communication and Sport, 3, 261-287.

Cranmer, G. A., Brann, M. y Bowman, N. D. (2014). Male athletes, female aesthetics: The continued ambivalence toward female athletes in EsPN's The body issue. International Journal of Sport Communication, 7(2), 145-165.

de Coubertin, Pierre (1912). Comienzos de la mujer en los Juegos Olímpicos. Recuperado de http://mujereseneldeporte.blogspot.com/2008/11/espiritu-olimpico.html.

D’Andraia, A. (2015). Diario de una chica fit: los secretos de la periodista de Para Ti. Ciudad Autónoma de Buenos Aires, Argentina: Atlántida.

Fernández, J. M. (2017, 12 de marzo). Trampolín Instagram, Revista Viva.

Garton, G. e Hijós, N. (2017). La mujer deportista en las redes sociales: un análisis de los consumos deportivos y sus producciones estéticas. Hipertextos. Capitalismo, Técnica y Sociedad en Debate, 5(8), 83-105.

Garton, G. e Hijós, N. (2018). "La deportista moderna": género, clase y consumo en el fútbol, running y hockey argentinos. Antípoda. Revista de Antropología y Arqueología, 30, 23-42.

Klein, N. (2015) [1999]. No logo: el poder de las marcas. Buenos Aires, Argentina: Paidós.

Rial, C. (2013). El invisible (y victorioso) fútbol practicado por mujeres en Brasil. Nueva Sociedad, 248, 114-126.

Rodríguez Díaz, Á. (2005). Trabajo y ocio: La civilización hacia el tiempo libre del deporte. Portal de las Ciencias de la Actividad Física y del Deporte. Recuperado de www.cafyd.com/HistDeporte/htm/pdf/2-32.pdf

Rodríguez, A. D. (2016). El gimnasio, el crossfit y el running aportan pistas para pensar un nuevo modo de individuación. Voces en el Fénix, 58, 50-55. 
Rubinich, L. (2011). Productores privilegiados de visiones del mundo. Nociones de libertad en disputa. En L. Rubinich y P. Miguel (eds.), Creatividad, economía y cultura en la Ciudad de Buenos Aires 2001-2010 (pp. 9-44). Buenos Aires, Argentina: Aurelia Rivera.

Sassatelli, R. (2012). Consumo, cultura y sociedad. Buenos Aires, Argentina: Amorrortu.
Silba, M. (2015, 21 de septiembre). Palermo villa. Juventudes y cultura popular. Anfibia.

Silba, M. (2017, 6 de febrero). Guerra y paz en paso de cumbia. Revista N.

Stebbins, R. A. (1997). Casual leisure: a conceptual statement. Leisure Studies, 16(1), 17-25. 